\title{
The future of specialty care in the US
}

\author{
Richard A Cooper
}

Most medical specialties face the problem of having too few practitioners to meet the growing needs of patients, with a projected shortage of 200,000 physicians across all specialties by 2025 . Rheumatology is no exception. To address this problem, the number of physicians being trained must increase by about 10,000 (40\%) annually (Cooper RA [2004] Ann Intern Med 141: 705-714). Yet, even if that were achieved over the next decade, the output of rheumatologists would not increase appreciably until 2015 at the earliest.

Some progress has been made at undergraduate level. Currently, 25 new medical schools (allopathic or osteopathic) are under development or have been opened in the US over the past 3-4 years. Together with the expansion of existing schools, these changes should produce approximately 6,500 additional graduates by 2020 . That number will be enough to fill all the existing residency positions, one-quarter of which are currently filled by international medical graduates. Without a similar expansion of graduate medical education (GME), however, the nation won't produce any additional physicians - rheumatologists or others.

Unfortunately, there has not been a parallel effort to expand GME. The main reason is that, during the 1990s, policy experts predicted a surplus of physicians and, in 1997, Congress capped Medicare's funding for residency positions at their 1996 levels. Medicare is a principal source of GME funding and, therefore, further growth in residency training was sharply curtailed. Now that shortages are upon us, it seems clear that the caps on GME must be lifted and residency programs must be once again extended (Cooper RA [2001] Ann Surg 246: 527-534), but little is happening to make that possible.
The proper

action now is

for Medicare to

fund additional

residency

positions under

the existing

formula

RA Cooper is Professor of Medicine and Senior Fellow at the Leonard Davis Institute of Health Economics, University of Pennsylvania, Philadelphia, $P A, U S A$.

\section{Competing interests \\ The author declared no} competing interests.

www.nature.com/clinicalpractice doi:10.1038/ncprheum0844
Why is more not being done? There are two major reasons. First, although most major professional organizations have called for the expansion of GME, some analysts believe there are already too many physicians. This conclusion is based on the notion that regional variation in physician services is due to 'supplierinduced demand' rather than the varying needs of patients. As they see it, rheumatologists (and other specialists) overuse the system to their own advantage. While this deduction might seem outrageous, it is lent weight by the imprimatur of the sponsoring institution-Dartmouth Medical School-and the sponsoring foundation-Robert Wood Johnson. Unfortunately, although fundamental weaknesses have been revealed (Cooper RA [2008] Bull Am Coll Surg 93: 11-18), bad ideas have a way of lingering.

The second reason that GME is not being expanded is that its organization and funding are so complex (Cooper RA [2001] Ann Surg 246: 527-534). Despite various recommendations for change, there has never been a broad-based re-examination of GME funding in the context of national health care goals, economic realities and the imperatives of residency and fellowship training. Such an assessment is sorely needed, but expansion of GME is even more sorely needed, and removing the caps cannot await a national consensus. The proper action now is for Medicare to fund additional residency positions under the existing formula, even if growth is limited to $10-15 \%$ while a national conversation proceeds. Neither 'Dartmouth doubletalk' nor GME's funding complexities, however, should delay an easing of the caps.

Rheumatology shares its future with that of the entire physician workforce. Propelling GME forward is a responsibility that rheumatologists must embrace-for the good of their specialty and their patients. 